American Journal of Applied Sciences 8 (10): 1019-1026, 2011

ISSN 1546-9239

(C) 2011 Science Publications

\title{
Visually Impaired Children's Acceptances on Assistive Courseware
}

\author{
${ }^{1}$ Nurulnadwan Aziz, ${ }^{1}$ Nur Hazwani Mohamad Roseli \\ and ${ }^{2}$ Ariffin Abdul Mutalib \\ ${ }^{1}$ Department of Academic, Faculty of Office Management and Technology, \\ University Technology MARA Terengganu, Dungun Campus (UiTM), \\ 23000 UiTM Dungun, Terengganu, Malaysia \\ ${ }^{2}$ School of Media Technology and Communication, \\ UUM College of Arts and Sciences, University Utara Malaysia, \\ 06010 UUM Sintok, Kedah, Malaysia
}

\begin{abstract}
Problem statement: The government of Malaysia is considering serious efforts in promoting the usage of computers among disabled people. Currently, the availability of computer applications especially related to creative contents for disabled people in Malaysia is infancy and very expensive. Research and expertise in the area of Assistive Technology (AT) in Malaysia is still uncommon and not extensively utilized. Therefore research involving special communities such as disabled people on the usage of electronic applications should be focused because records show that their population populations are increasing. Hence, this research will be tailored for Visually-Impaired (VI) learners. In Malaysia, visual impairment is one of the highest registered disabilities. Approach: This study presents an ongoing project that determines whether the VI children can accept the Assistive Courseware (AC) as one of the effective tools in their learning process. Specification identification, AC development and testing and evaluation are three activities involved in this study. In addition, data have been collected through qualitative approaches. Results: The results highlight four important elements for incorporated in an AC for VI children. Through the testing and evaluation, it was found that the VI children accept the AC due to interesting usage of audio, graphic, text and easy navigation method. Conclusion: In a nutshell, the positive responses prove that the AC not only exposes the VI children to the world of technology but also educates them in terms of interpersonal skills, intrapersonal skills and motivation. The recommended future work is to produce a much comprehensive AC which focuses on interactivity, various multimedia elements, multiple intelligence elements and multiple stages of exercise in granting value-added AC not only for VI children in Malaysia but also to other world VI communities in the world.
\end{abstract}

Key words: VI children, visual impairment, Assistive Technology (AT), Assistive Courseware (AC), user acceptance, general interaction, specification identification, multiple intelligence

\section{INTRODUCTION}

The potential of creative content industry is certainly recognized by the government of Malaysia through its' Information Technology and Communication (ICT) sector to achieve high income country status (Muhyiddin, 2010). In fact, in the 2010 budget speech, the Prime Minister of Malaysia stated that "the creative content industry has the potential to be further developed and contribute to economic growth" (Mohd-Najib, 2009).

It is continue in the 2011 budget speech the Prime Minister of Malaysia encouraging the researchers and developers to contribute in this sector by allocating research grants and funds to create unique creative contents (Mohd-Najib, 2010).

Corresponding Author: Nurulnadwan Aziz, Department of Academic, Faculty of Office Management and Technology, University Technology MARA Terengganu, Dungun Campus (UiTM), 23000 UiTM Dungun, Terengganu, Malaysia 
Am. J. Applied Sci., 8 (10): 1019-1026, 2011

Table 1: Registered disabled people according to types of disability. 2002-2009

\begin{tabular}{|c|c|c|c|c|c|c|c|}
\hline \multirow[b]{2}{*}{ Types of disability } & \multicolumn{7}{|l|}{ Year } \\
\hline & 2002 & 2003 & 2004 & 2005 & 2006 & 2007 & 2009 \\
\hline Visual impairment & 14.738 & 14.154 & 15.364 & 16.211 & 18.258 & 20.039 & 23.378 \\
\hline Hearing impairment & 21.981 & 22.728 & 24.712 & 26.470 & 29.522 & 31.715 & 35.368 \\
\hline Physical impairment & 41.311 & 45.356 & 51.090 & 58.371 & 66.250 & 73.559 & 86.458 \\
\hline Mental* & 43.042 & 49.340 & & & & & \\
\hline Learning problem & & & 57.483 & 66.906 & 76.619 & 85.812 & 100.180 \\
\hline Cerebral palsy & & & 34.000 & 623.000 & 887.000 & 1.787 & 3.250 \\
\hline Other1.017 & 1.077 & 1.934 & 4.335 & 5.983 & 7.338 & 9.897 & \\
\hline Total122.089 & 132.655 & 150.617 & 172.916 & 197.519 & 220.250 & 258.918 & \\
\hline
\end{tabular}

At the same time, initiatives in assisting the disabled to use technologies have been growing in most countries including Malaysia. Obliviously, technology evolves very fast. Similarly, from time to time the number of people with disabilities keeps on increasing. They should be respected as part of the resources for the country. In making sure they are not left behind from technology advancement, the researchers have to come out with various types of technologies, which are referred to as Assistive Technology (AT). It is hoped that the AT is able to assist the disabled in carrying out their daily life. There are many examples of AT developed since the past few decades in the forms of hardware and software (Elmetwaly, 2010; Nordin and Ali, 2009). Most of these technologies are for accessing information and service including learning process (Elmetwaly, 2010; Roseli et al., 2010; Aziz et al., 2009). Druin (2009) defines AT as any device that could assist any impairment or disabled person in performing a task. This definition is also agreed by (Druin, 2009; Elmetwaly, 2010; Judge et al., 2011) who defines AT as technological devices or software that are designed to assist people with disabilities. In addition, Americans with Disabilities Act of 1990 stated that employers, professional educators and industries are responsible to provide reasonable accommodations to assist the disabled (Belkasmi et al., 2010). Wheelchairs, hearing aids, screen readers and special educational software are some examples of AT that have been developed (Jabr and Omari, 2010; Druin, 2009). Unluckily, the disabled people have to spend a big amount of money to afford for the AT because they are very expensive in the market. As a result the usage of AT are still limited and usually used by the high income people (Aziz et al., 2009; Wong and Cohen, 2011).

On the other hand, UNESCO acknowledges that children with disabilities deserve to have quality education similar with the normal students. Due to this, equipping disabled children with education and life skills training can help them to achieve a brighter future in life.
Social Welfare Department of Malaysia reported that approximately 258,918 people were registered as disabled in Malaysia. In June 2002, there were 14,738 registered VI people, then the number increased to 23,378 in 2009 (Table 1). According to Nordin and Ali (2009), VI inclusive of students with partially sight, low vision, legally blind and totally blind.

From the facts in Table 1, it could be deduced that from the year 2002 until 2009, the registered VI people in Malaysia was increasing rapidly. Although the number is increasing very fast, still the development of creative content especially in education for this kind of people is deficient. In education, VI students are still neglected compared to normal students in accessing knowledge (Wong and Cohen, 2011). Furthermore, most developers and experts put very little concerns in creating creative contents that address VI children as part of the users. In views of national initiatives, creating creative contents is consistently emphasized by the government for national growth and it has obviously been stated in the Ninth Malaysia Plan, further the importance is continued in the Tenth Malaysian Plan. Lack of contents for the VI learners creates a huge gap between them and normal students.

In response to the short of content creation for VI learners, this study attempts to identify the possibilities of designing $\mathrm{AC}$ for the VI learners. It aims at identifying the characteristics of AC for VI children and to develop a prototype of AC for VI children. Also, it determines whether users accept the formulated characteristics through the prototype in a user testing procedure.

\section{MATERIALS AND METHODS}

In this study, a series of activities were carried out, as shown illustratively in Fig. 1. The figure explains that this study involves three phases which are specification identification, development of $\mathrm{AC}$ and testing and evaluation. In the first phase, documents were studied and interviews with teachers of VI children were carried out. From this phase, data 
regarding to characteristics of $\mathrm{AC}$ for $\mathrm{VI}$ children were gathered. The characteristics are important to ensure users' requirements are adapted in AC especially in designing the interface (Druin, 2009; Rotman et al., 2011). Semi-structured interview (Fraenkel and Wallen, 2009) was done with teachers of VI children in one of the special education institution in Malaysia. The question of interview regarding to characteristics of AC for VI children has been divided into four elements which are audio, formatting style and text, graphic and animation and general interaction. Multimedia elements including text, graphic and sound which inserted in AC can give more advantages to VI children to interact with the courseware (Rjoub et al., 2009). The characteristics gathered from the literature study and interviews are listed as follow:

Audio: the VI children depend $100 \%$ on audio to know everything that happened around them (Khan, 2009). Therefore the use of audio should be clear and concise. In addition, the usage of sound effect could enhance their understanding in learning process (Yi-Chun and Pi-Ching, 2009).

Formatting style and text: Font must be standard face, while font size must be at least 20-point and above (Argyropoulos et al., 2009). In terms of color, VI people have different perception of color compared to normal people. Therefore the combination of font color and background color must be highly contrast (Ruiter et al., 2011). The teachers suggest that the combination of yellow and dark green is a good pair for them (Masrom et al., 2011).

Graphic and animation: the important information in the form of graphic should be bigger (Nordin and Ali, 2009). Another characteristic is the use of graphics in one screen should be minimized.

General interaction: the use of mouse was not practical for VI children (Masrom et al., 2011). Keyboard is the best device for them to interact with computer application (Masrom et al., 2011). The instruction provided by the AC also must be clear enough.

By utilizing the data gathered in phase 1, the prototype of AC was developed. The development part follows steps named as Int view methodology. There were 10 steps in pre-development phase, while seven steps in the development phase. During step 10, the storyboard of the prototype was constructed. The required pictures and audio as well as other media elements were specified. The specifications in the storyboard which were accomplished by hand writing were then transformed into other more detailed specifications in the designing activities. The images were obtained from various sources such as self-design, bought from commercial CD and downloaded from the Internet. Adobe Photoshop CS3 was used to edit the images as needed. Audio editing was done using Sound Forge and finally the AC was developed using Adobe Flash. In the context of this study, the AC was designed by applying special instructional approach and provides special elements for VI children to learn and enjoy lesson similarly like normal children. These special elements differentiate it from other coursewares that are available in the market (Abdullah et al., 2009; Aziz et al., 2009). Figure 2-6 depict four samples of AC snapshots developed in this study labeled with unique characteristics found in phase 1 . Phase 3 of the study involves testing procedures including user task analysis and interview. It is to measure the levels of user acceptance of the prototype.

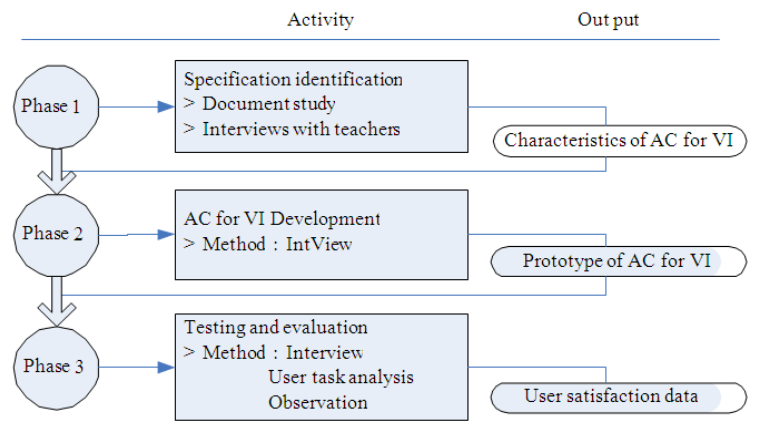

Fig. 1: Summary of activities

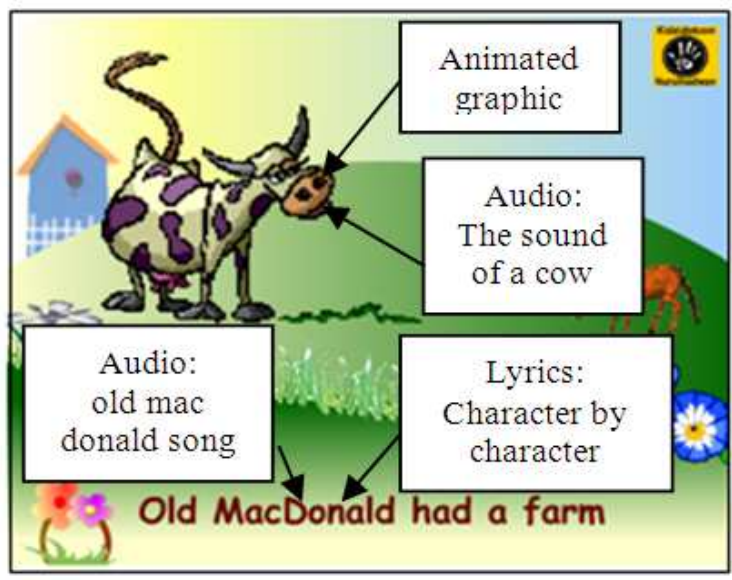

Fig. 2: Snapshot of Module 1(Learning through songs) 


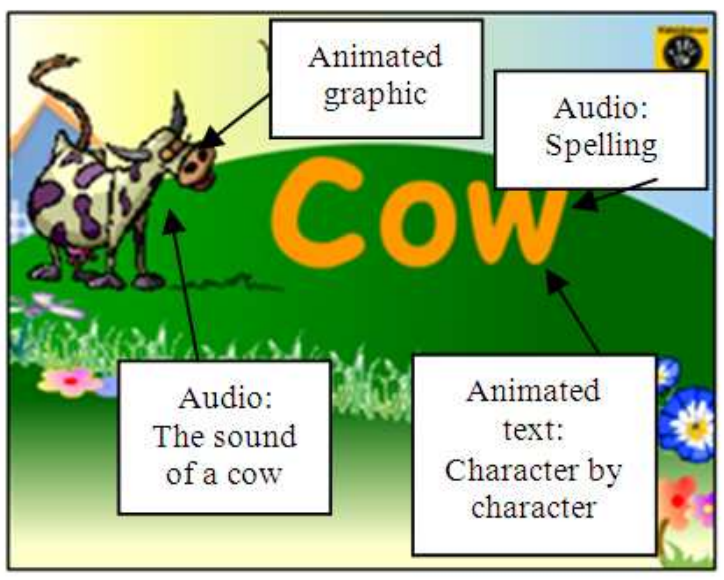

Fig. 3: Snapshot of module 2 (Spelling)

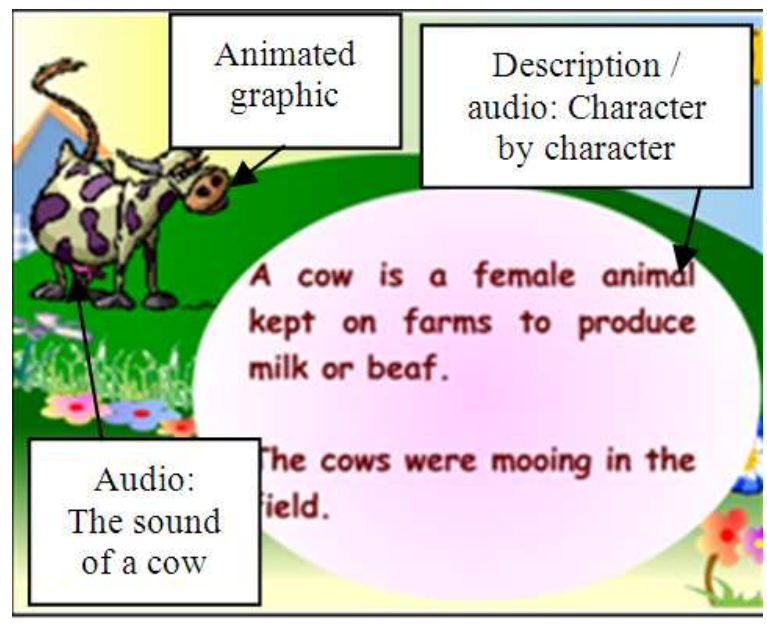

Fig. 4: Snapshot of Module 2 (Description of animals)



Fig. 5: Snapshot of exercise module

\section{RESULTS}

Testing was conducted during a class session in a school computer laboratory that is equipped with two big speakers, one personal computer and one LCD projector for the instructor. The subjects of the testing were $17 \mathrm{VI}$ students from one of the special education institutions in Malaysia. They were between 7 and 12 years old. The VI students that involve in the test included low vision and totally blind children. Every student was equipped with a set of personal computer in front of them and one set of headphone. They were set to sit next to another. The laboratory was locked to make sure all the participants were not disturbed by the outside environment in order to obtain valid results. The AC was installed into each personal computer. Qualitative data were gathered through observation, interview and practical testing. Results are summarized in tables.

Observation: Observation was done twice in same settings and period. The 17 samples involved in investigating their behavior on AC. During the experiments first the user was briefed about the purpose of study and mentioned about anonymity. Then the AC was played to the user by instructor. The data as listed in Table 2 have been gathered through observations over the body language. Think-aloud protocol was applied, in which the participants were encouraged to speak-aloud all their ideas about the AC while using it to understand their inner feelings (Buranat, 2011). Also, data from observation were gathered through annotating their comments and behaviors (Buranat, 2011; Yahya et al., 2009; Abdellateif et al., 2011).

Interview: Interview was done after the observation. Firstly the subjects were briefed the purpose of interview. The instructor plays the $\mathrm{AC}$ in front of the class. All the subjects were request to pay attention to the AC. Subjects were interviewed based on four elements provided by AC. Results of the interviews were based on the four elements provided by the AC which are audio, formatting style and text, graphic and animation and general interaction. The results are summary in Table 3-6.

Practical testing: Practical testing has been done through Exercise Module. For this type of testing firstly subjects also were briefed the purpose of testing. 
Table 2: Data gathered through observing subjects' behavior

Behavior criteria Observation description

Fun The subjects were found happy interacting with the AC through the way they sing together and utilizing the features in the AC

Laugh The subjects were found laughing and smiling at certain parts of AC

Enjoyable When the AC finish played to them, the subjects ask to repeat it for the second time

Enthusiastic Everyone is found enthusiastic because AC is very new to them

Excited The subjects were found very excited interact with the AC

Humor The subjects were making jokes with their friends when interacting with the AC

Curiosity The subjects were found try to operate the AC on their own even not instructed

Focus $\quad$ The subjects were found pay attention to the lesson especially to the audio

Motivation The subjects were found start motivated after the instructor introduced them the second song

Difficulties Some parts of the AC were found difficulties especially when the attribute was animated

Confuse There are certain parts of AC where the subjects were found confuse especially for those who are totally blind

Passive One of the subjects was found passive all the times

Table 3: Characteristics and level of acceptance for audio Level of acceptance

\begin{tabular}{|c|c|c|c|}
\hline \multirow[b]{2}{*}{ Characteristic } & \multicolumn{3}{|c|}{ Level of acceptance } \\
\hline & High & Moderate & Low \\
\hline Depend on the audio & $\sqrt{ }$ & & \\
\hline Can hear sound clearly & $\sqrt{ }$ & & \\
\hline $\begin{array}{l}\text { Using background music to assist in } \\
\text { the learning process }\end{array}$ & & & $\sqrt{ }$ \\
\hline $\begin{array}{l}\text { Using sound effect to enhance } \\
\text { interaction with the AC }\end{array}$ & $\sqrt{ }$ & & \\
\hline
\end{tabular}

Table 4: Characteristics and level of acceptance for formatting style and text

\begin{tabular}{|c|c|c|c|}
\hline \multirow[b]{2}{*}{ Characteristic } & \multicolumn{3}{|c|}{ Level of acceptance } \\
\hline & High & Moderate & Low \\
\hline Font size is large enough & $\sqrt{ }$ & & \\
\hline Font type is easy to understand & $\sqrt{ }$ & & \\
\hline Font face is easy to understand & & & $\sqrt{ }$ \\
\hline $\begin{array}{l}\text { Font colour contrast with the } \\
\text { background color }\end{array}$ & & & \\
\hline Animated text is acceptable & & & $\sqrt{ }$ \\
\hline
\end{tabular}

Table 5: Characteristics and level of acceptance for graphic and animation Level of acceptance

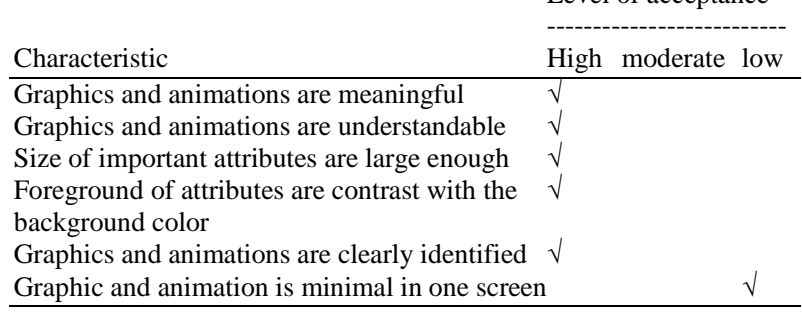

Table 6: Characteristics and level of acceptance for general interaction

\begin{tabular}{llll}
\hline & Level of acceptance & \\
& High & Moderate & Low \\
Characteristic & & $\sqrt{ }$ \\
\hline $\begin{array}{l}\text { Full used of keyboard } \\
\text { Directions and instructions in } \\
\text { the AC is explicit }\end{array}$ & & $\sqrt{ }$ \\
\hline
\end{tabular}

Table 7: Level of acceptance for practical testing Level of acceptance

\begin{tabular}{llll} 
Testing criteria & High $(\%)$ & Moderate $(\%)$ & Low $(\%)$ \\
\hline Practical testing & 35.3 & 41.2 & 23.5 \\
\hline
\end{tabular}

Exercise Module was played to them by instructor. They were allowed to browse the Exercise Module at their own convenience. Table 7 summarizes the results.

\section{DISCUSSION}

Generally all the data were gathered in the subjects natural environment in which is the subjects were sitting beside their peers. It was identical as in their routine classes. Their peers were allowed to accompany them, with a hypothesis that they will communicate with their peers when interacting with the AC. This study focuses on user acceptance of the developed prototype. Due to this, this study treats their communication as valuable data.

Observation: The AC contains three modules, but for the observation testing two modules were introduced to the subjects which are Module 1: Learning through songs and Module 2: Learning wild animals, domestic animals and pets. Module 3: Exercise was not introduced to them at this session because it is suitable for practical testing. The subjects were demonstrated with the $\mathrm{AC}$ by the instructor in front of the class. Although everyone was not familiar with computer but the subjects were found enthusiastic to learn because the AC is very new to them. In the school, the VI students have never been exposed to any multimedia application including courseware. Therefore, to enhance their motivation the AC was played twice. In the first round, Module 1: Learning through songs was played to them and it was found that $100 \%$ of the subjects were a little bit confused but at the same time they were in curiosity mode. They were not able to grasp the songs fully but they were trying to capture the songs slowly and tried to adapt themselves into the current situation. When the songs were played for the second time, $91.15 \%$ of them were motivated. It was seen through their body language when they sang together with the $\mathrm{AC}$ and clapped their hand follow the 
rhythm of the songs. Then Module 2: Learning wild animals, domestic animals and pets was introduced to them. Their excitement was seen through the way they fight to be closed to the display. It was noted that $90.13 \%$ of them gave good responds. When come to the spelling part the subjects tried to spell together with the $\mathrm{AC}$ and tried to guess the name of the animals that appeared on the screen. At the same time they stayed focused to the speakers to hear the animal's sound carefully. Unfortunately the animation text created in the $\mathrm{AC}$ was too fast for them. It was very hard for the subjects to grasp the words. During the play, it was seen that some of the subjects were also chatting to each other when necessary, clarifying about the contents in the show. From the observation, this study interprets that the VI children gain not only the explicit contents in the shows, but also more than that such as motivation, interpersonal skills and intrapersonal skills. This matter also gave opportunity to them to learn best at their own pace (Aziz et al., 2011; Manoharan et al., 2009; Savita and Nur-Athirah, 2011).

Interview: Results of the interview are discussed as follow based on four elements as stated in the result section.

Audio: Audio is the most important element for the VI people (Khan, 2009; Masrom et al., 2011). Based on the results, all of the subjects depend $100 \%$ on the audio to recognize the graphics and texts that appear on the screen. They could hear the sound provided by the AC clearly. As found in the interviews, sound effects can enhance their interaction with the AC. In contrast, the background music should be avoided because it disturbs the subjects' focus because they were found not able to differentiate the background music with desired information.

Formatting style and text: There are five unique characteristics of formatting styles and texts found in this study and they were incorporated in the AC. The results show that most subjects agreed that the font size provided by the $\mathrm{AC}$ is large enough for them to read on computer screen. The study found that the best font size for VI people is 18-point and above. It is also found that the font type and font face provided by the AC are easy for them to understand. In addition, it was also noted that the VI people can only accept standard font face and the best font type for the VI students is serif font (example: Comic Sans). Otherwise, the VI people (except for totally blind people) will face difficulties and are confused in reading the text. Colors also play important roles in supporting the VI students especially those with low vision and color blindness (Nordin and Ali, 2009). As found in the interviews, the subjects could accept the contrast colors between font color and background color designed in the AC. The level of contrast colors between background and font is very important for VI students to recognize the texts (Nordin and Ali, 2009). The subjects suggest that the combination between black and white will produce a good contrast color compared to red and green; it is a poor contrast color because these two colors are too dark for them. Besides that, most of the subjects suggested that outlining text can enhance their understanding. Subjects also commented that the animated text should be avoided so that they can focus on the text. In other words, animated text will make them more confused.

Graphics and animations: Based on the interview, most of the characteristics for graphics and animations provided by the AC are acceptable by the subjects and the levels of acceptance are high. But this is not including the last characteristic, it was noted that $100 \%$ of the subjects agreed that AC should avoid collecting too much information in terms of graphics and animation on one screen. This is because VI students will be confused, when they have to focus on many things, especially if the graphics are animated. Size is another important characteristic to be considered when designing the AC for VI children. VI children will give more attention to bigger attributes among all (Nordin and Ali, 2009). This suggests that the most desired attribute should be emphasized in terms of size.

General interaction: Utilizing $100 \%$ of keyboard is the best method for VI children to interact with all types of computer applications including AC (Masrom et al., 2011). The use of mouse is not practical for them (Masrom et al., 2011). In this study, after testing with the prototype, the results show that the level of acceptance for full use of keyboard is low. Factors that contribute to this result are the keyboard usage that provided by this AC itself is less efficient. There is just one scene of AC that allows the subjects to interact physically with AC. Another factor is based on the interview $64.7 \%$ of the subjects are not computer literate. Furthermore, directions and instructions provided by the AC were not explicit for VI children. Hence, during the testing process the subjects could not depend on the keyboard only to do the exercises but they needed assistance from the instructors.

Practical testing: practical testing offer the subjects to do the exercise provided in Module 3. The results 
showed that $35.3 \%$ of the subjects achieved good performance in doing exercise; all these subjects were low vision students. During the practical testing the instructor assisted the subjects when the use of mouse was necessary in Module 3. Another $41.2 \%$ of the subjects motivated to do the exercise but they need the instructors to facilitate them all of the time and $23.5 \%$ of the remaining subjects were not able to do the exercise at all. From the outcomes found in the practical testing, this study interprets that motivation, computer literacy and the development of AC itself influence the level of user acceptance.

\section{CONCLUSION}

This study has successfully identified the main characteristics for incorporation in an $\mathrm{AC}$ for $\mathrm{VI}$ children. Different kinds of users have different needs for the content of courseware. For VI children all of these unique characteristics have been grouped into four elements which are audio, formatting style and text, graphic and animation and general interaction. Although, the developed prototype could not incorporate all the characteristics, the results obtained from the test have successfully proven that there are several unique characteristics that need to be standardized when designing an AC for VI children. The AC has been propose to VI children and observed on their reactions through think aloud protocol and body language. Interview and practical testing also have been done to them. Overall the levels of their acceptance were very positive upon the AC. The AC not only exposes the VI children to the world of technology but also develop their interpersonal skills, intrapersonal skills and motivation. In this study the data were gathered at one of the institution in Malaysia to understand the context at initial level. It could be strengthened by widening the study scope to the whole part of Malaysia so that the evidence is more accurate.

The future recommended is to produce a much comprehensive version of $\mathrm{AC}$ by incorporating all the standard guidelines with multiple intelligence theory. It will be supported with various multimedia elements and multiple stages of exercise in giving value added courseware for the VI children not just in Malaysia but to the world VI community as a whole.

\section{REFERENCES}

Abdellateif, M., A.B.M. Sultan, M. A. Jabar and R. Abdullah, 2011. A technique for quality evaluation of e-learning from developers perspective. Am. Econ. Bus. Admin., 3: 157-164. DOI: 10.3844/ajebasp.2011.157.164
Aziz, N., N.H.M. Roseli, E.S. Eshak and A.A. Mutalib, 2011. Assistive courseware for the visually impaired based on theory of multiple intelligence and SECI model. Am. J. Econ. Bus. Admin., 3: 150-156. DOI: 10.3844/ajebasp.2011.150.156

Abdullah, M.H.L., H. Syariffanor and P. Shahril, 2009. MyLexics: An assistive courseware for dyslexic children to learn basic malay language. Newsletter ACM SIGAACCESS Accessibility Comput., 95: 39. DOI: $10.1145 / 1651259.1651260$

Argyropoulos, V.S., G.D. Sideridis, G. Kouroupetroglou and G. Xydas, 2009. Auditory discriminations of typographic attributes of documents by students with blindness. Bri. J. Visual Impairment, 27: 183-203. DOI: $10.1177 / 0264619609106360$

Aziz, N., N.H.M. Roseli and A.A. Mutalib, 2009. Assistive courseware for visually-impaired. Lect. Notes Comput. Sci., 5857: 905-915. DOI: 10.1007/978-3-642-05036-7_86

Belkasmi, M.G., T. Bouchentouf, M. Azizi and A. Benazzi, 2010. Modeling projects in E-learning course: a case of an information technology project. J. Comput. Sci., 6: 823-829. DOI: 10.3844/jcssp.2010.823.829

Buranat, S. 2011. Effects of an educational scenario exercise on participants' competencies of systemic thinking. J. Soc. Sci., 7: 51-62. DOI: 10.3844/jssp.2011.51.62

Druin, A., 2009. Mobile Technology for Children: Designing for Interaction and Learning. 1st Edn., Morgan Kaufmann, USA., ISBN: 978-0-12374900, pp: 353.

Elmetwaly, H.M.M., 2010. A system for e-learning processes management. J. Comput. Sci., 6: 689692. DOI: $10.3844 /$ jcssp. 2010.689 .692

Jabr, M.A. and H.K.A. Omari, 2010. E-learning management system using service oriented architecture. J. Comput. Sci., 6: 285-295. DOI: 10.3844/jcssp.2010.285.295

Judge, S., Z. Robertson and M. Hawley, 2011. The limitations of speech control: Perceptions of provision of speech-driven environmental controls. J. Assistive Technol., 5: 4-11. DOI: 10.5042/jat.2011.0096

Khan, Z.N., 2009. Cognitive and non-cognitive characteristics as determinants of success in professional courses at undergraduate stage. J. Soc. Sci., 5: 212-215. DOI: 10.3844/jssp.2009.212.215

Manoharan, R., K. Vivekanandan and V. Sundaram, 2009. A software agent for speech abiding systems. J. Comput. Sci., 5: 90-96. DOI: 10.3844/jcssp.2009.90.96 
Mohd-Najib, A.R., 2010. The 2011 Budget Speech. Mohd-Najib, T.A.R., 2009. The 2010 Budget Speech.

Muhyiddin, Y., 2010. Peruntukan Tambahan Industri Kandungan Kreatif.

Nordin, M.J. and A.M. Ali, 2009. Indoor navigation and localization for visually impaired people using weighted topological map. J. Comput. Sci., 5: 883889. DOI: 10.3844 jessp.2009.883.889

Rjoub, A., Y. Eyadat, A. Ghazawi, B. Tall and N. Sharou et al., 2009. A multi-form multiple choice editor exam tool based on HTML website and artificial intelligence techniques. J. Comput. Sci., 5: 405-412. DOI: 10.3844/jcssp.2009.405.412

Roseli, N.H.M., N. Aziz and A.A. Mutalib, 2010. The enhancement of assistive courseware for visually impaired learners. Proceedings of International Symposium on Information Technology, Jun. 1517, IEEE Xplore Press, Kuala Lumpur, Malaysia, pp: 1-6. DOI: 10.1109/ITSIM.2010.5561368

Rotman, D., S.Vieweg, S.Yardi, E. Chi and J. Preece et al., 2011. From slacktivism to activism: Participatory culture in the age of social media. Proceedings of Annual Conference on Human Factors in Computing Systems, May 7-12, ACM New York, USA, pp: 819-822. DOI: $10.1145 / 1979742.1979543$
Ruiter, S., H. Nakken, M. Janssen, B.V.D. Meulan and P. Looijestijn, 2011. Adaptive assessment of young children with visual impairment. Bri. J. Visual Impairment, 29: 93-112. DOI: 10.1177/0264619611402766

Savita, K.S. and A.P. Nur-Athirah, 2011. Malay sign language courseware for hearing impaired children in Malaysia. World Applied Sci. J., 12: 59-64.

Wong, M.E. and L. Cohen, 2011. School family and other influences on assistive technology use access and challenges for students with visual impairment in Singapore. Bri. J. Visual Impairment, 29: 130144. DOI: 10.1177/0264619611402759

Yahya, A., J. Ramli, S. Hashim, M.A. Ibrahim and Z. Zakaria, 2009. Analysis of students with psychiatric disabilities in higher education. J. Soc. Sci., 5: DOI: 10.3844/jssp.2009.362.369

Yi-Chun, C. and C. Pi-Ching, 2009. The effect of english popular songs on learning motivation and learning performance. WHAMPOA-An Interdisciplinary J., 56: 13-28. 